\title{
A Comparison of Nucleus Accumbens Neuronal Firing Patterns during Cocaine Self-Administration and Water Reinforcement in Rats
}

\author{
R. M. Carelli and S. A. Deadwyler \\ Center For The Neurobiological Investigation of Drug Abuse, Department of Physiology and Pharmacology, Neuroscience \\ Program, Bowman Gray School of Medicine, Wake Forest University, Winston-Salem, North Carolina 27157
}

The firing patterns of nucleus accumbens (NA) neurons in the rat were recorded during cocaine self-administration and responding for water. Recordings were obtained from permanently implanted multiple-electrode arrays (eight microwires) inserted bilaterally into rostral portions of the NA in subjects $(n=18)$ exhibiting stable cocaine self-administration $(0.33 \mathrm{mg} /$ infusion), and during stable responding for water reinforcement. Electronically isolated and identified NA neurons exhibited four distinct patterns of phasic activity relative to the reinforced response. Three of these firing patterns were observed during both cocaine self-administration and water reinforcement sessions. Response-related activity was categorized by cells that showed an anticipatory increase in firing rate during the preresponse phase (type $P R$ ), and by cells that were excited (type $R F_{E}$ ) or inhibited (type $R F_{1}$ ) following the response in the reinforcement phase. $P R$ and $R_{E}$ cells showed significantly reduced peak firing during cocaine self-administration, compared to similar cells in water reinforcement sessions. A fourth type of NA firing pattern (type PR+RF) was observed only in cells recorded during cocaine self-administration sessions (Carelli et al., 1993b). PR+RF neurons exhibited two distinct peaks, one preceding the response and terminating at response completion (like PR cells), and a second peak immediately following the response (like $\mathbf{R F}_{\mathrm{E}}$ cells) with an inhibitory period between the two peaks (like $\mathrm{RF}_{1}$ cells). The findings are discussed in terms of the role of the NA in mediating the reinforcing properties of both cocaine and water.

[Key words: nucleus accumbens, neuron types, cocaine self-administration, water reinforcement, chronic recording, reward]

The nucleus accumbens (NA) is an important neural substrate involved in mediating the rewarding properties of cocaine, a psychomotor stimulant that is widely abused in humans and readily self-administered in animals (Koob and Goeders, 1988; Gawin, 1991; Koob, 1992; Woolverton and Johnson, 1992). In particular, the reinforcing properties of cocaine appear to depend upon the dopaminergic projection from the ventral teg-

\footnotetext{
Received Mar. 24, 1994; revised June 13, 1994; accepted June 16, 1994.

This research was supported by NIDA DA05535-02 to R.M.C. and DA0119 and DA06634 to S.A.D. We thank Virginia King for catheter implants, Dr. Linda Porrino and Leslie Vogt for histology, Dr. Robert Hampson for help with statistics, and Terrence Bunn for computer programming assistance.

Correspondence should be addressed to Dr. Regina M. Carelli, Department of Physiology and Pharmacology, Bowman Gray School of Medicine, Wake Forest University, Medical Center Boulevard, Winston-Salem, NC 27157.

Copyright (c) 1994 Society for Neuroscience $0270-6474 / 94 / 147735-12 \$ 05.00 / 0$
}

mental area (VTA) to the NA. For example, cocaine self-administration is increased in rats following pretreatment with dopamine antagonists (deWit and Wise, 1977; Roberts and Vickers, 1984; Koob and Goeders, 1988; Britton et al., 1991; Corrigall and Coen, 1991; Hubner and Moreton, 1991) or following microinjection of a dopamine antagonist directly into the NA (Maldonado et al., 1993). In addition, cocaine selfadministration was attenuated in rats with 6-OHDA-induced damage in the NA (Roberts et al., 1980; Pettit et al., 1984) and VTA (Roberts and Koob, 1982) and kainic acid lesions of the NA (Zito et al., 1985). Likewise, microdialysis studies have shown concomitant increases in NA dopamine during cocaine self-administration in rats (Pettit and Justice, 1989, 1991).

A number of studies also implicate the NA in mediation of the reinforcing properties of food and water. For example, postmortem neurochemical analyses have revealed increases in NA dopamine metabolism in rats food-deprived and given $1 \mathrm{hr}$ access to food (Heffner et al., 1980) and in response to conditioned stimuli previously paired with food (Blackburn et al., 1986). In vivo microdialysis studies revealed increases in extracellular concentrations of DA and its metabolites in the NA during the initiation and/or maintenance of feeding in fooddeprived rats (Hernandez and Hoebcl, 1988; Radhakishun et al., 1988; McCullough and Salamone, 1992) and during water consumption in rats (Young et al., 1992). Likewise, autoradiographic techniques using a radiolabeled glucose analog revealed significant metabolic increases in the NA during drinking in thirsty rats (Gonzalez-Lima et al., 1993).

A functional role of the NA in mediating the rewarding properties of both appetitive and drug reinforcement is supported by electrophysiological studies in behaving animals. In monkeys, NA neurons exhibited phasic increases in firing rate in anticipation of or following responding for liquid reinforcement (Apicella et al., 1991; Schultz et al., 1992). Recently, NA neurons exhibited phasic increases in firing rate relative to the cocainereinforced response in self-administering rats (Peoples et al., 1989; Peoples and West, 1990; Carelli et al., 1993a,b; Chang et al., 1994). However, there have been no systematic investigations of differences between NA neuronal activity during appetitive versus drug reinforcement conditions. The purpose of the present study was to investigate the neuronal firing patterns of NA neurons during cocaine self-administration and compare them to patterns of NA activity exhibited during response contingent water delivery in rats.

\section{Materials and Methods}

Cocaine self-administration. Male Sprague-Dawley rats (Harlan), approximately $90-120 \mathrm{~d}$ old and weighing $275-350 \mathrm{gm}$, were used as 
subjects $(n=14)$. Animals were housed individually and maintained at their preoperative body weights by regulation of food and water intake. Surgical and behavioral training procedures for cocaine selfadministration have been described in detail elsewhere (Carelli et al., 1993b). Briefly, subjects were anesthetized with ketamine hydrochloride $(100 \mathrm{mg} / \mathrm{kg})$ and xylazine hydrochloride $(20 \mathrm{mg} / \mathrm{kg})$ and a catheter inserted into the jugular vein and then routed subcutaneously to the back and attached to coupling assembly. The fluid injection assembly (syringe pump) was connected to a swivel system in the home and experimental chambers that enabled intravenous infusion of heparinized saline every $2 \mathrm{hr}$ in the home cage, and cocaine infusion during self-administration sessions.

One week following catheter implantation, rats were trained to selfadminister cocaine during experimental sessions conducted in a $43 \times$ $43 \times 53 \mathrm{~cm}$ Plexiglas chamber housed within a commercial soundattenuated cubicle (Industrial Acoustics Co., Bronx, NY). The beginning of the session was signaled by the onset of a cue light (Sylvania Pilot Light; positioned $6.5 \mathrm{~cm}$ above the lever) and extension of a retractable lever (Coulborn Instruments, Lehigh Valley, PA). Depression of the lever (fixed ratio 1 schedule, FR1) resulted in intravenous administration of cocaine $(0.33 \mathrm{mg} /$ infusion, dissolved in sterile heparinized saline vehicle) over a $5.8 \mathrm{sec}$ period via a computer-controlled syringe pump (Razel Scientific Inst., model A). Initiation of drug delivery was signaled by termination of the cue light over the lever and simultaneous onset of a tone $(67 \mathrm{~dB}, 1 \mathrm{kHz})$-houselight $(25 \mathrm{~W})$ conditioned stimulus (CS) complex that remained on for $20 \mathrm{sec}$ after the drug-reinforced response. During the $20 \mathrm{sec}$ post-reinforcement interval, lever presses did not activate the pump. Stable self-administration behavior within 2-3 hr sessions was characterized by $16-30$ infusions administered at regular (5-8 $\mathrm{min}$ ) interinfusion intervals (INTs) and was established in all subjects within 14-21 d of pretraining, at which time microwire electrodes were surgically implanted within the NA (see below). Different aspects of NA firing related to cocaine self-administration have been reported previously for a small number of cells (Carelli et al., 1993b). The present study provides a more extensive characterization and classification of NA fring patterns during cocaine self-administration and compares this activity to NA neuronal firing patterns exhibited during water reinforcement.

Water reinforcement experiments. Male Sprague-Dawley rats $(n=8)$ were water deprived and trained to press a second lever for water reinforcement in the same experimental chamber. Of the eight subjects, four rats were previously implanted with microwire electrode arrays and tested during cocaine self-administration sessions. For these subjects, training on the water reinforcement task began approximately 5$7 \mathrm{~d}$ following the last self-administration experiment. The remaining four subjects were trained only on the water reinforcement task.

During water reinforcement sessions, water availability was also signaled by a cue light (Sylvania Pilot Light) positioned $6.5 \mathrm{~cm}$ above the extended retractable lever (Coulborn Instruments, Lehigh Valley, PA). This lever was situated $16 \mathrm{~cm}$ to the right of the lever used during selfadministration sessions. A plastic drinking spout was mounted between the two levers, $2 \mathrm{~cm}$ near the floor of the chamber. Subjects were initially trained to lever press on a FR1 schedule for $0.05 \mathrm{ml}$ of water delivered via a solenoid valve into the plastic drinking spout. A 15 sec timeout period following each reinforced response signaled termination of the cue light over the lever and the onset of the tone-houselight CS used in cocaine self-administration sessions. A differential reinforcement of low rates of responding (i.e., "DRL") schedule of reinforcement was in effect during the timeout period such that each lever press was not reinforced and reset a timeout clock for an additional $15 \mathrm{sec}$. Stable responding for water was characterized by 100 trials completed within $30-50 \mathrm{~min}$ with regular interresponse intervals (INTs) of 18-25 sec. Performance at this level was established in all subjects within 10-14 $\mathrm{d}$ of training, at which time electrode implantation was performed.

Electrophysiological recordings. Once behavioral responding was stable, subjects were anesthetized with ketamine hydrochloride $(100 \mathrm{mg} /$ $\mathrm{kg}$ ) and xylazine hydrochloride $(20 \mathrm{mg} / \mathrm{kg})$ and prepared for chronic extracellular recording in the NA (Carelli et al., 1993b). Electrodes were purchased from a commercial source (NB Labs, Denison, TX) and constructed according to specification. Custom designed arrays of eight microwires $(50 \mu$ diameter; tip separation, $0.25-0.50 \mathrm{~mm}$; span, $1 \times 1$ $\mathrm{mm}$ ) were permanently implanted bilaterally into the NA (AP +1.7 $\mathrm{mm}$, ML $1.5 \mathrm{~mm}$, DV $6.0-7.5 \mathrm{~mm}$, relative to bregma, level skull; Paxinos and Watson, 1986). Each array also contained a ground wire that was inserted 3-4 $\mathrm{mm}$ into brain, ipsilateral to the array and approximately $5 \mathrm{~mm}$ caudal to bregma.
Following electrode implantation, presurgical behavioral performance was reestablished, and neuronal activity was recorded during all subsequent behavioral sessions. Before the start of each session, the subject was connected to a flexible recording cable attached to a commutator (Josef Biela Eng, Anaheim, CA) that allowed unrestrained movement within the chamber. The headstage of the recording cable contained 16 miniature unity-gain field effect transistors. NA activity was differentially recorded between active and inactive electrodes from the 16 permanently implanted microwires. The inactive electrode was examined before the start of each session to verify the absence of neuronal spike activity and served as the differential electrode for other electrodes with cell activity. Isolation and discrimination of neuronal activity was accomplished using a "Neurophysiological Event Processor" (NEP), capable of on-line processing of up to 64 channels (Spectrum Scientific, Dallas, TX). Multiple window-discrimination modules and high-speed analog-to-digital (A/D) signal processing in conjunction with computer software enabled isolation of neuronal signals based on waveform analysis. The NEP incorporates an array of digital signal processors (DSPs) for continuous spike recognition. The DSPs provided a continuous parallel digital output of neuronal spike events to a Motorola Delta 2616 minicomputer system (Motorola, Inc. Microsystems, Tempe, AZ). The Motorola Delta 2616 was used for on-line analysis and control of behavioral aspects of the experiment. The parameters for isolation and discrimination of single-unit activity were determined and saved using the NEP software package prior to the first recording session. Waveform parameters could be recalled on subsequent days and modified as needed, for example, to discriminate "new" neurons that appeared on a given microwire electrode, or to change the inactive electrode.

Data analysis. Neuron data were characterized via strip charts, rasters, and perievent histograms (PEHs) showing the activity of each neuron during a $20 \mathrm{sec}$ time interval that bracketed the drug-or water-reinforced response. An analysis of variance (ANOVA; followed by pairwise comparisons) revealed that neurons could be differentially classified into four types of neuronal firing patterns observed relative to the reinforced response as a function of differential firing rates within four time epochs in each PEH. The four time epochs within each PEH were (1) "baseline," defined as the time period $(-10$ to $-7.5 \mathrm{sec})$ before the initiation of the reinforced response; (2) "response," defined as the time period $(-2.5$ sec to 0 ) immediately before and during execution of the reinforced response; (3) "reinforcement," defined as the time period $(0$ to +2.5$)$ immediately following the response to $2.5 \mathrm{sec}$ later; and (4) "recovery," defined as the time period from 7.5 to $10 \mathrm{sec}$ after the reinforced response. The three-way ANOVA provided statistical evaluation of differences in neuronal firing patterns (types of neurons) observed under each reinforcer condition (cocaine or water). Factors within the ANOVA consisted of reinforcer condition (cocaine or water), type of neuronal firing pattern, and time epoch. All statistical analyses were performed using PC-sAS (SAS Institute, Cary, NC).

Histology. Following the completion of the last experiment, animals were anesthetized with sodium pentobarbital $(50 \mathrm{mg} / \mathrm{kg})$ and a $10 \mu \mathrm{A}$ current passed for $10 \mathrm{sec}$ through one or two recording electrodes in the array on each side of the brain. Only microwires exhibiting large isolated spikes and well-characterized firing patterns during a behavioral session were chosen for marking. The rat was perfused with $10 \%$ formalin and the brain was removed and blocked. All sections $(50 \mu \mathrm{m})$ were counterstained with Prussian blue to reveal a blue dot reaction product corresponding to the location of the electrode tip (Green, 1958). Alternating sections were stained for either thionin or tyrosine hydroxylase. Unmarked electrode tip locations were determined by estimation of termination of the microwire track in serial sections. Marked and unmarked electrode tip locations were plotted for all subjects $(n=18)$ on coronal sections taken from the stereotaxic atlas of Paxinos and Watson (1986) using a computer graphics program.

\section{Results}

Behavioral performance: cocaine and water reinforcement The performance characteristics of 18 rats were investigated during lever pressing for cocaine or water reinforcement. Cocaine self-administration sessions consisted of 16-30 trials completed within 2-3 hr. The mean interresponse interval (INT) was $5.68 \pm 0.24 \mathrm{~min}$ in well-trained rats. Cocaine self-administration behavior typically conformed to the following scenario: after completion of the drug-reinforced response, subjects po- 
sitioned themselves next to the lever, or in a corner of the chamber, and engaged in stereotypic behaviors; toward the end of the INT, subjects moved toward the lever, eventually completing the lever press (FR1) requirement for pump initiation and cocaine infusion. During water reinforcement sessions, the mean INT in well-trained rats was $21.29 \pm 0.82 \mathrm{sec}$ and rcsponse rates were much higher than cocaine sessions. During the tone-houselight signaled $15 \mathrm{sec}$ timeout period following a water-reinforced response, animals typically moved around the chamber and stayed away from the lever as the result of training to the DRL contingency in effect. However, as soon as the tonehouselight CS terminated, subjects moved quickly toward the lever and executed the water-reinforced lever press. Water reinforcement sessions consisted of 100 trials completed within $35-50 \mathrm{~min}$.

Figure 1 illustrates cumulative lever pressing behavior of an animal during water reinforcement and cocaine self-administration sessions. The cumulative record in the top portion of Figure 1 shows the first 20 min (52 trials) of the water reinforcement session that consisted of 100 trials with a mean INT of $21.34 \pm 1.12 \mathrm{sec}$. The cumulative record in the bottom of Figure 1 shows the response pattern during the first hour (15 trials) of a cocaine self-administration session ( 21 trials, mean INT of $4.32 \pm 0.31 \mathrm{~min}$ ). The rate of pressing for water was much higher than for cocaine.

\section{Comparison of NA neuronal firing patterns during cocaine and water reinforcement}

The firing characteristics of NA neurons were assessed during responding for water ( $n=124$ cells) and cocaine self-administration ( $n=244$ cells). In general, cells fired at lower rates during cocaine self-administration (overall mean $=3.23 \pm 0.35 \mathrm{~Hz}$ ) than during water reinforcement (overall mean $=3.97 \pm 0.42$ $\mathrm{Hz}$ ). Only $24 \%$ (58 neurons) of 244 cells recorded during cocaine self-administration showed phasic activity associated with the drug-reinforced response (Carelli et al., 1993b). The remaining $76 \%$ (186 cells) exhibited no change in firing pattern (increase or decrease) relative to the cocaine-reinforced lever press. Similarly, 26\% (32 neurons) of 124 cells recorded during water reinforcement sessions showed phasic firing patterns related spccifically to the reinforced response while the remaining $74 \%$ (92 cells) did not.

There were clear distinctions in the type of firing pattern exhibited by NA neurons during cocaine self-administration and water reinforcement sessions. Based on $\mathrm{PEH}$ inspection and statistical analysis (Table 1), four different neuronal firing patterns were observed. Three of these patterns occurred in NA cells recorded during both cocaine and water reinforcement conditions. An increase in firing rate well before the occurrence of the reinforced response designated some neurons as preresponse (PR) firing cells. Other types of NA neurons showed an excitation $\left(R F_{E}\right)$ or inhibition $\left(R F_{1}\right)$ in firing rate immediately following the reinforced response. Mean firing rates for all three cell types across the four time epochs (baseline, response, reinforcement, and recovery) are presented in Table 1 . A threeway ANOVA revealed a significant overall effect of reinforcement condition, cell type, and time epoch on NA firing $\left(F_{23,228}\right.$ $=9.96, p<0.001)$. Across all time epochs and NA cell types, neuronal firing rates during cocaine self-administration (mean $=3.82 \pm 0.92 \mathrm{~Hz}$ ) were significantly lower than firing rates during water $($ mean $=5.05 \pm 1.17 \mathrm{~Hz})$ reinforcement sessions $\left(F_{1,228}=14.48, p<0.001\right)$. There was a significant effect of cell
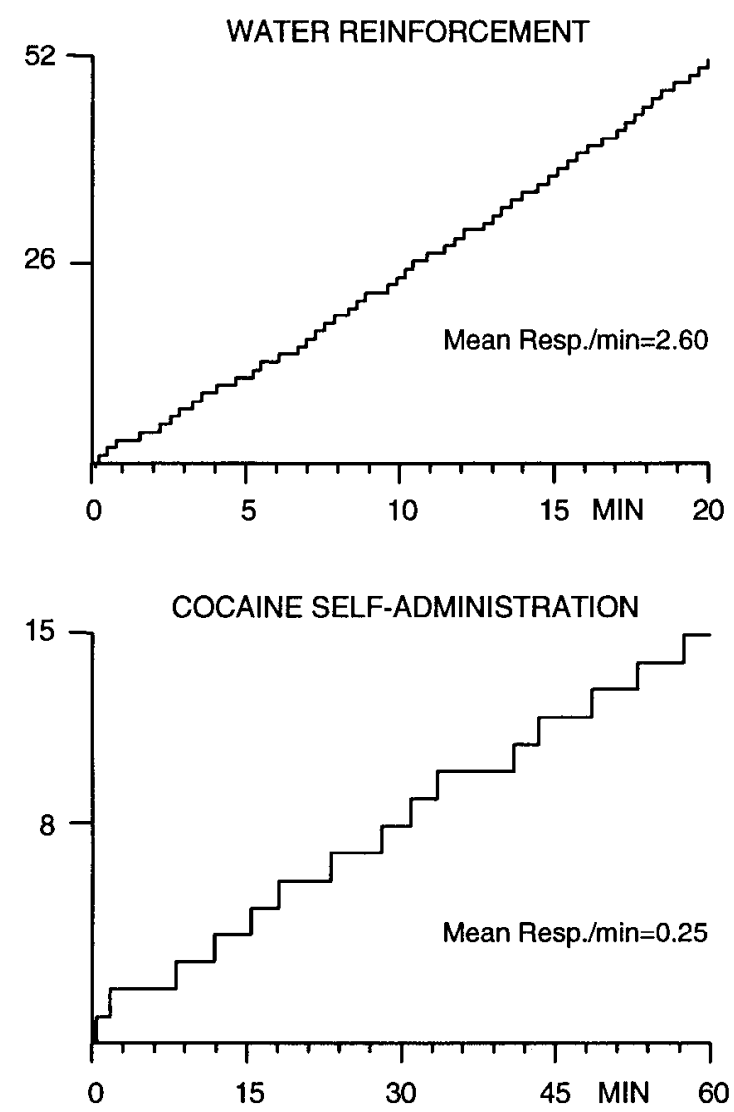

Figure 1. Cumulative record showing the behavioral (lever press) response pattern of the same subject during water reinforcement and cocaine self-administration sessions. Each upward deflection represents one (reinforced) lever press (FR1). The $y$-axis is the number of lever presscs. Top, Cumulative record showing the distribution of lever pressing during $20 \mathrm{~min}$ of the water reinforcement session $(52$ trials). The mean INT for the entire session (100 trials $/ 36 \mathrm{~min}$ ) was $21.34 \pm 1.12$ sec. Bottom, Cumulative record showing behavioral response pattern during $1 \mathrm{hr}$ of a cocaine self-administration session ( 15 trials). The mean INT for the entire session ( $21 \mathrm{trials} / 2 \mathrm{hr}$ ) was $4.32 \pm 0.31 \mathrm{~min}$. Resp., responses.

type $\left(F_{2,228}=9.06, p<0.001\right)$ as well as a significant effect of time epoch $\left(F_{3,228}=7.27, p<0.001\right)$ and a significant interaction between cell type and time epoch $\left(F_{6,228}=26.16, p<0.001\right)$. A more detailed description of each type of NA neuronal firing pattern under both water and cocaine reinforcement conditions is presented below.

$P R$ cells. PR cells exhibited clear anticipatory increases in firing 3-5 sec prior to the occurrence of the response for water and cocaine (Table 1, Response). Examples of individual cells showing PR neuronal firing patterns are presented in Figure 2 across a $20 \mathrm{sec}$ time base (top) and an extended (480 sec) time base (bottom). Firing rates for all PR cells increased from a mean baseline of approximately $2-3 \mathrm{~Hz}$ to a mean peak firing rate of $7-13 \mathrm{~Hz}$ immediately preceding the reinforced response (Table 1, Response). Firing rates decreased abruptly toward zero at the time of responsc cxccution, and remaincd low in the reinforcement phase. Baseline firing returned differentially during the recovery phase as a function of reinforcer condition (Fig. 2). The increase in PR cell firing rate during the response period compared to baseline period was significant for both the cocaine $\left(F_{1,228}=16.14, p<0.01\right)$ and water reinforcement conditions $\left(F_{1,228}=35.80, p<0.01\right)$, as shown in Table 1 . The peak firing 
Table 1. Mean \pm SEM of NA peak $\left(P R\right.$ and $\left.R F_{E}\right)$ and trough $\left(R F_{I}\right)$ firing rates across four time epochs relative to the cocaine- or waterreinforced response

\begin{tabular}{|c|c|c|c|c|c|c|}
\hline \multirow[b]{2}{*}{ Epoch (sec) } & \multicolumn{2}{|l|}{ Type PR } & \multicolumn{2}{|l|}{ Type $R_{F}$} & \multicolumn{2}{|l|}{ Type $R F_{1}$} \\
\hline & $\begin{array}{l}\text { Cocaine } \\
(n=19) \\
\end{array}$ & $\begin{array}{l}\text { Water } \\
(n=10)\end{array}$ & $\begin{array}{l}\text { Cocaine } \\
(n=12) \\
\end{array}$ & $\begin{array}{l}\text { Water } \\
(n=12)\end{array}$ & $\begin{array}{l}\text { Cocaine } \\
(n=3)\end{array}$ & $\begin{array}{l}\text { Water } \\
(n=7)\end{array}$ \\
\hline \multicolumn{7}{|l|}{ Baseline } \\
\hline-10 to -7.5 & $2.27 \pm 0.35$ & $3.37 \pm 0.84$ & $1.61+0.56$ & $1.22 \pm 0.44$ & $7.41 \pm 1.73$ & $7.87 \pm 2.25$ \\
\hline \multicolumn{7}{|l|}{ Response } \\
\hline-2.5 to 0 & $7.02 \pm 1.26^{*}$ & $13.13 \pm 2.96^{*}$ & $0.67 \pm 0.30$ & $0.70 \pm 0.16$ & $5.77 \pm 1.47$ & $7.36 \pm 1.57$ \\
\hline \multicolumn{7}{|l|}{ Reinforcement } \\
\hline 0 to 2.5 & $0.48 \pm 0.14$ & $1.32 \pm 0.58$ & $6.60 \pm 1.49^{*}$ & $9.97 \pm 1.67^{*}$ & $1.12 \pm 0.45$ & $3.05 \pm 1.24$ \\
\hline \multicolumn{7}{|l|}{ Recovery } \\
\hline 7.5 to 10 & $0.81 \pm 0.21$ & $3.66 \pm 0.98$ & $2.71 \pm 0.76$ & $1.21 \pm 0.40$ & $9.34 \pm 1.90$ & $7.74 \pm 2.13$ \\
\hline
\end{tabular}

Data are presented as mean \pm SEM. Boldface type denotes significant difference $(p<0.05)$ compared to baseline within the same column. ${ }^{*}$ denotes significant difference $(p<0.05)$ between cocaine versus water within the same epoch and type.

rate of PR cells during water reinforcement sessions was significantly higher than the peak firing rate during cocaine selfadministration $\left(F_{1,228}=18.37, p<0.01\right)$. The proportion of neurons exhibiting PR phasic firing patterns was $31 \%(n=10$ cells) for water reinforcement and $39 \%(n=23$ cells $)$ for cocaine self-administration. The onset time for peak anticipatory firing in PR cells ranged from 1 to $9 \mathrm{sec}$ for water and from 2 to 6 sec prior to the cocaine-reinforced response; however, in some cases there was a gradual increase in firing rate $30-60 \mathrm{sec}$ prior to the cocaine-reinforced response (Fig. 2, bottom right). Firing in PR neurons in both reinforcement conditions terminated within $500 \mathrm{msec}$ of response completion. A subset $(n=5)$ of PR cells observed during cocaine self-administration sessions exhibited anticipatory firing that actually terminated 2 sec prior to completion of the reinforced response.

Another difference between PR neurons recorded during co-
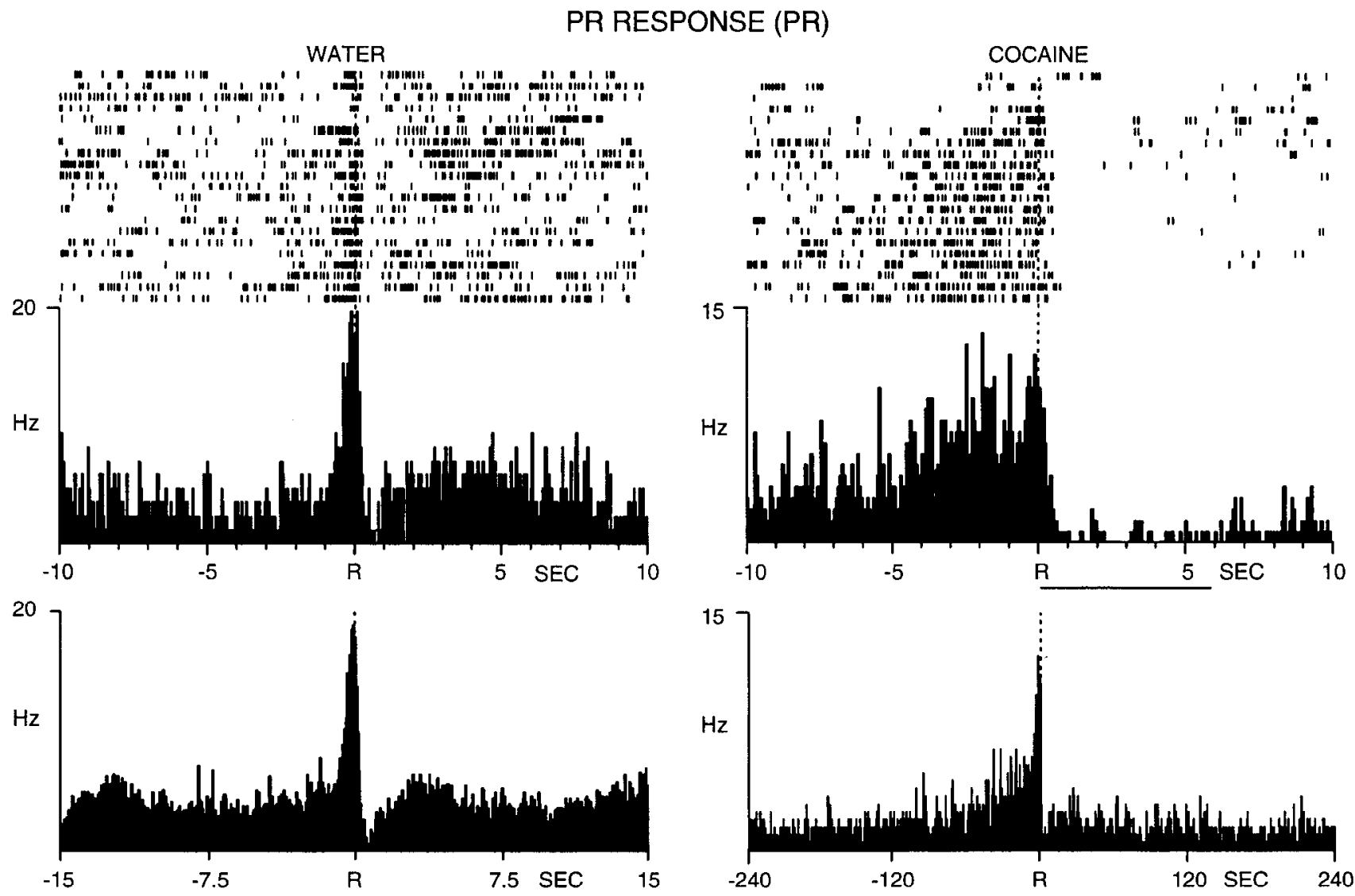

Figure 2. Preresponse (PR) NA firing pattern shows an anticipatory discharge relative to reinforced lever presses in both water and cocaine reinforcement sessions. Top: Left, Single trial raster and PEH of a PR NA neuron during water-reinforced responding (mean INT $=16.59 \pm 0.58$ sec). Right, Another NA neuron in a different animal during a cocaine self-administration session (mean INT $=5.04 \pm 0.39$ min). Bottom, Same PR neurons displayed in the raster/PEH above showing activity across an extended time base that encompasses time between lever presses. The lower PEHs exclude activity in which lever presses occurred within the intervals on either side of the reinforced response. Each PEH contains 500 bins in all figures. Duration of drug infusion $(5.8 \mathrm{sec})$ is indicated by horizontal line below cocaine PEH (top right). Reinforced responses are indicated by $R$ at dashed vertical line in each PEH. 


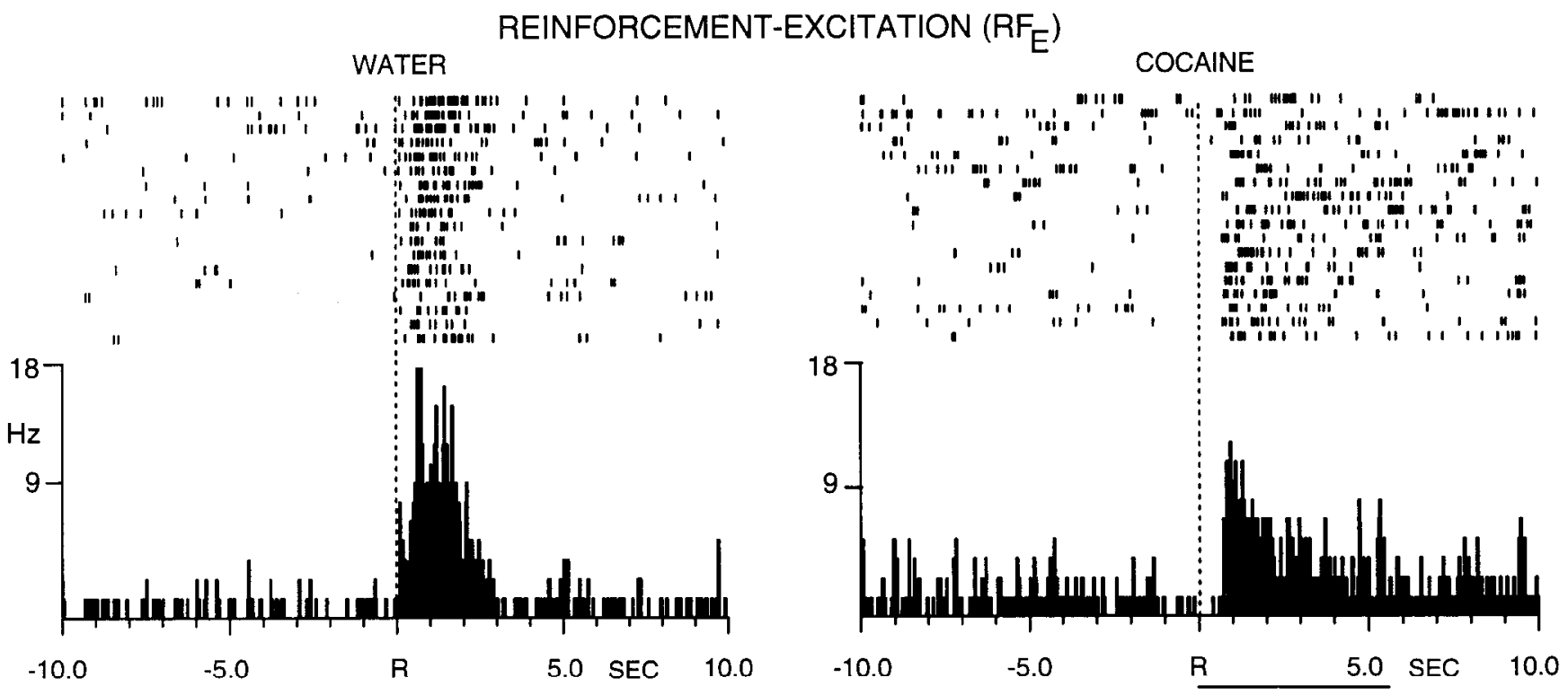

Figure 3. Reinforcement-excitation $\left(\mathrm{RF}_{\mathrm{E}}\right) \mathrm{NA}$ neuronal firing pattern in which elevated firing rates were observed immediately following the water- or cocaine-reinforced response. $L e f l$, Raster and $\mathrm{PEH}$ of a single $\mathrm{RF}_{\mathrm{E}} \mathrm{NA}$ neuron illustrating increased discharge for 3 sec after occurrence of the water-reinforced response (mean INT $=18.14 \pm 1.7 \mathrm{sec}$ ). Right, Raster and PEH of an $\mathrm{RF}_{\mathrm{E}} \mathrm{NA}$ neuron in a different animal showing longerlasting increased discharge following the cocaine-reinforced response (mean INT $=8.67 \pm 1.08 \mathrm{~min}$ ). Drug pump duration (5.8 sec) is indicated by horizontal line below the $\mathrm{PEH}$. Reinforced responses are indicated by $R$ at dashed vertical line in each PEH.

caine versus water reinforcement was that a subset $(n=12)$ of PR cells recorded during cocaine self-administration exhibited a prolonged suppression of firing during the recovery period (Table 1, Fig. 2). In contrast, all PR neurons during water reinforcement exhibited only a short-lasting inhibition and had recovered baseline firing rates by 7.5-10 sec following the response as shown in Table 1.

$R F_{E}$ cells. The second type of firing pattern exhibited by NA cells showed excitatory increases during the reinforcement phase $\left(R F_{E}\right)$. The percentage of $R F_{E}$ cells to total phasic neurons recorded during water reinforcement was $47 \%(n=15$ cells). For cocaine self-administration, the proportion was $21 \%(n=12$ cells). Firing in $\mathrm{RF}_{\mathrm{E}}$ cells was significantly increased over baseline firing for both water $\left(F_{1,228}=34.50, p<0.01\right)$ and cocaine $\left(F_{1,228}=11.27, p<0.01\right)$ at the time of reinforcement delivery (Table 1). The peak firing rate of $R F_{E}$ cells during water reinforcement sessions was significantly higher than the peak firing rate during cocaine self-administration $\left(F_{1,228}=5.10, p<0.05\right)$. Examples of individual cells showing $\mathrm{RF}_{\mathrm{E}}$ firing patterns during water and cocaine reinforcement are presented in Figure 3. The mean onset time for peak firing in $\mathrm{RF}_{\mathrm{E}}$ neurons recorded during water reinforcement sessions ( $n=15$ cells) was $408 \pm 16 \mathrm{msec}$ following the response with an mean duration of elevated firing of $3.04 \pm 0.52 \mathrm{sec}$ following the response (Fig. 3, left). $\mathrm{RF}_{\mathrm{E}}$ neurons recorded during cocaine self-administration $(n=12$ cells) could be divided into two groups. The first group $(n=7)$ exhibited a short-lasting increase in firing rate within the same time domain as $\mathrm{RF}_{\mathrm{E}}$ cells recorded during water reinforcement. The second group ( $n=5$ ) exhibited a prolonged increase in firing rate that began $700 \pm 12 \mathrm{msec}$ following the response that persisted 40-180 sec (Fig. 3, right).

$R F_{I}$ cells. The third type of neuronal firing pattern observed in NA neurons during both reinforcement conditions was a pronounced, short-lasting inhibition immediately following the occurrence of the reinforced response $\left(\mathrm{RF}_{\mathrm{I}}\right)$. Mean firing rate for $R_{F_{1}}$ cells decreased significantly during the reinforcement period compared to baseline firing rates for both cocaine $\left(F_{1,228}\right.$ $=4.45, p<0.05)$ and water $\left(F_{1,228}=6.11, p<0.05\right)$, as shown in Table $1 . \mathrm{RF}_{\mathrm{I}}$ firing rates did not significantly differ between cocaine and water reinforcement conditions during either the reinforcement period $\left(F_{1,228}=0.59, p>0.05\right)$ or the recovery period $\left(F_{1,228}=0.40, p>0.05\right)$. The mean onset time of the response inhibition of $\mathrm{KF}_{\mathrm{I}}$ cell firing during cocaine self-administration sessions was $140 \pm 98 \mathrm{msec}$ after response completion with a mean duration of $2.1 \pm 0.19 \mathrm{sec}$ following the drugreinforced response. The mean onset time of the inhibitory response of type $\mathrm{RF}_{\mathrm{I}}$ neurons recorded during water reinforcement sessions was $257 \pm 68 \mathrm{msec}$ after the response with a mean duration of $1.93 \pm 0.25 \mathrm{sec}$. During cocaine self-administration sessions, neurons showing this firing pattern (Fig. 4) exhibited significantly higher baseline firing rates than PR cells $\left(F_{1,228}=\right.$ $5.14, p<0.05)$ and $\mathrm{RF}_{\mathrm{E}}$ cells $\left(F_{1,228}=6.07, p<0.05\right)$. Similarly, during water reinforcement sessions, $\mathrm{RF}_{\mathrm{l}}$ cell baseline firing rates were significantly higher than $\mathrm{PR}$ cells $\left(F_{1,228}=6.28, p<0.05\right)$ and $\mathrm{RF}_{\mathrm{E}}$ cells $\left(F_{1,228}=14.70, p<0.05\right)$. However, $\mathrm{RF}_{\mathrm{I}}$ cell baseline firing rates during cocaine self-administration were not significantly different from $\mathrm{RF}_{\mathrm{I}}$ cell baseline firing rates recorded during water reinforcement $\left(F_{1,228}=0.03, p>0.05\right) . \mathrm{RF}_{\mathrm{I}}$ cells comprised $22 \%$ ( $n=7$ cells) of the total phasic neurons during water reinforcement sessions and $9 \%(n=5$ cells) of cocaine phasic firing ncurons.

$P R+R F$ cells, cocaine sessions only. A distinct and unique type of NA cell firing pattern was exhibited by a large proportion of cells $(n=18)$ only during cocaine self-administration sessions. These cells displayed two distinct firing peaks, one preceding the response and terminating just prior to response execution (PR-like) and a second short-duration (100 msec) peak that followed completion of the response $\left(\mathrm{RF}_{\mathrm{E}}-\mathrm{like}\right)$. A third feature of $\mathrm{PR}+\mathrm{RF}$ cells was that the dual peak firing pattern appeared to reflect an intervening inhibitory period $\left(\mathrm{RF}_{\mathrm{I}}\right.$-like) at the time of response execution. Of the 18 cells of this type recorded in five rats, nine were recorded during sessions utilizing an FR1 


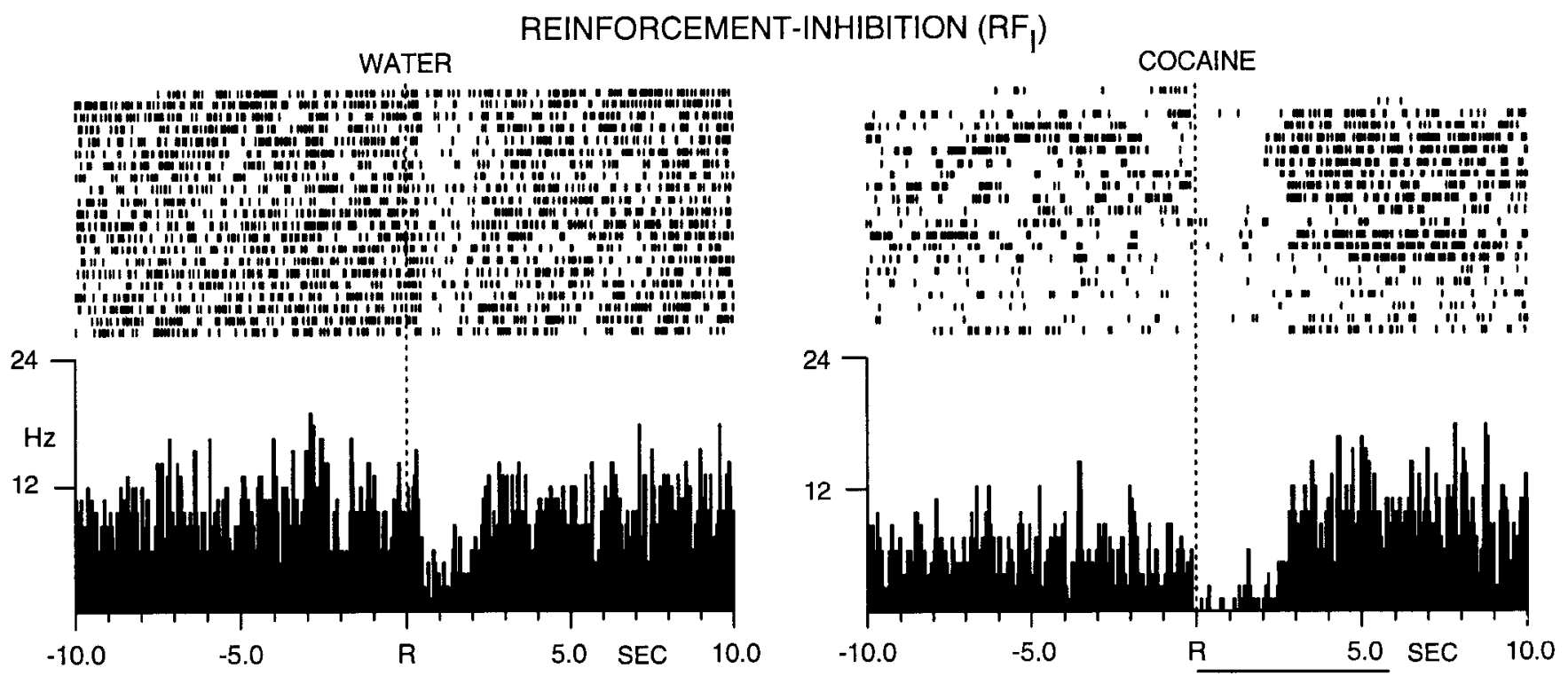

Figure 4. Reinforcement-inhibition $\left(\mathrm{RF}_{1}\right)$ NA neuronal firing pattern in which NA neurons exhibited an inhibition in firing rate immediately following completion of the water- or cocaine-reinforced response. Left, Raster and PEH showing inhibition of RF, NA cell firing immediately following the water-reinforced response (mean INT $=26.38 \pm 1.5 \mathrm{sec}$ ). Right, Raster and PEH showing a similar inhibition in firing rate recorded in a different animal immediately following the cocaine self-administration response (mean INT $=6.81 \pm 0.22 \mathrm{~min})$. Drug pump duration $(5.8$ $\mathrm{sec}$ ) and reinforced response are indicated as before.

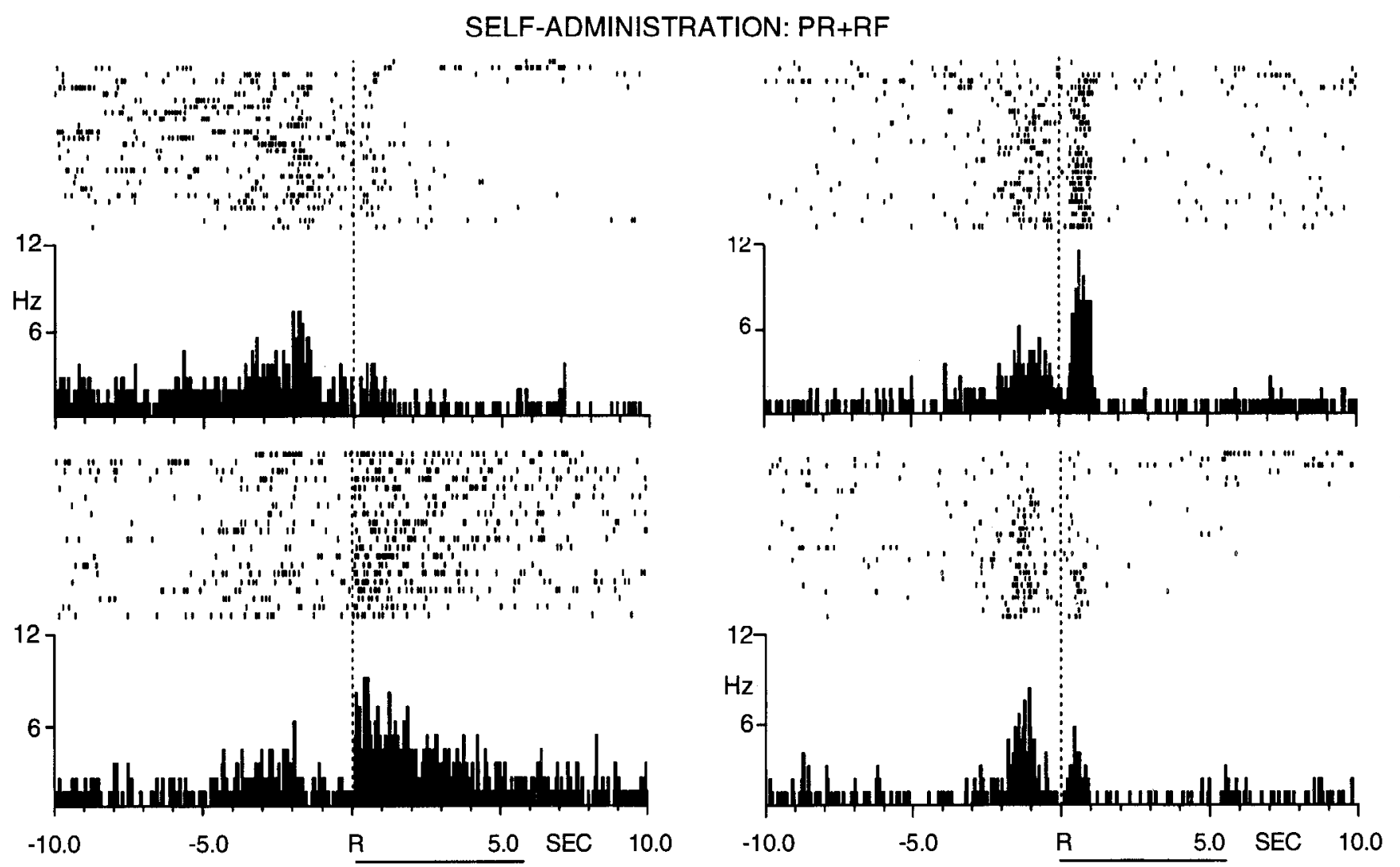

Figure 5. Examples of four different $P R+R F$ NA neurons recorded during cocaine self-administration sessions. Each $P R+R F$ neuron exhibited two distinct firing peaks, one preceding the response and terminating at response execution and the second peak immediately following the response. Left, Rasters and PEHs showing two examples of PR+RF NA neurons recorded in different animals. Mean INTs $=5.40 \pm 1.07$ min (top) and $5.49 \pm 0.55 \mathrm{~min}($ bottom). Right, Rasters and PEHs showing examples of two other PR +RF NA neurons simultaneously recorded in the same animal from different electrode wires during a cocaine self-administration session (mean INT $=5.15 \pm 0.53 \mathrm{~min}$ ). 


\section{WATER}
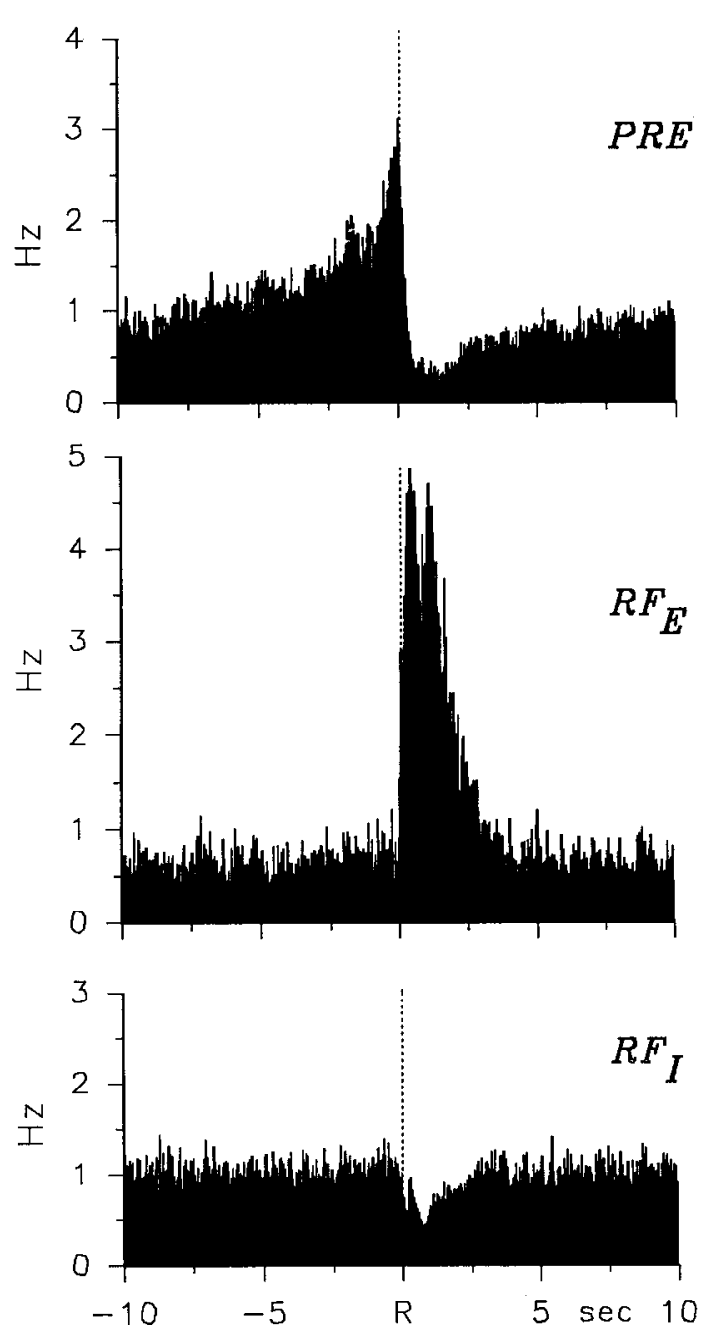

COCAINE
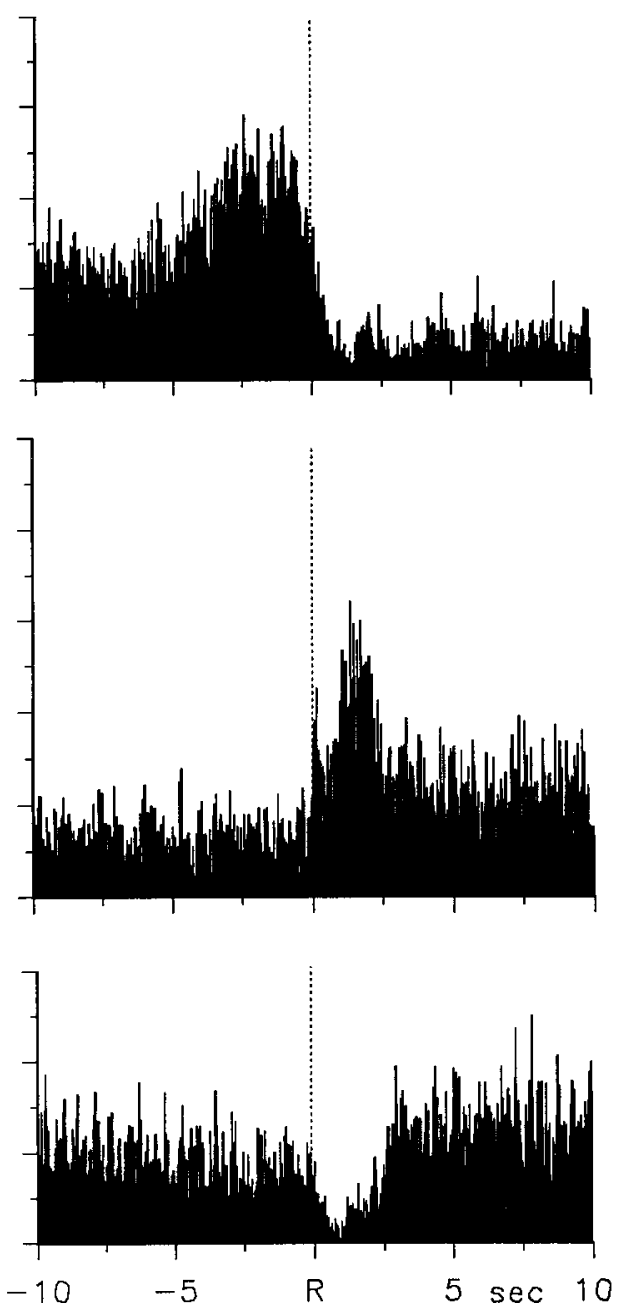

Figure 6. Composite PEHs of normalized firing of all $\mathrm{PR}, \mathrm{RF}_{\mathrm{E}}$, and $\mathrm{RF}_{\mathrm{I}}$ cells for water reinforcement and cocaine self-administration sessions normalized relative to its respective "baseline" (see Table 1) rates that was designated as $1.0 \mathrm{~Hz}$. These PEHs therefore reflect the relative increase in firing of each cell type irrespective of absolute firing rate. Under both water and cocaine reinforcement conditions, the complementary nature of the relative firing patterns of each cell type is apparent and similar. Duration of drug infusion is indicated by horizontal line below PEHs for cocainc sclf-administration (right). Reinforccd responses arc indicated by $R$ at dashed vertical line in cach PEH.

schedule of reinforcement and the remaining nine cells were recorded in two animals trained on FR4 or FR 10 schedules in addition to FR1. This neuronal firing pattern designated $P R+R F$, shown in Figure 5 for four different cells (FR1 schedule), was not observed in any of the 124 cells recorded during the water reinforcement condition, suggesting a possible specificity for cocaine self-administration. A previous report showed that the two peaks were controlled by different processes: the first primarily correlated with initiation of responding even if the response requirement differed, while the second peak was consistently associated with the onset of drug delivery (Carelli et al., 1993b).

PR $+\mathrm{RF}$ cells comprised $31 \%(n=18$ cells $)$ of all phasic firing cells recorded during cocaine self-administration sessions. The mean onset time for the first pcak in the PR + RF firing pattcrn of the FR1 requirement was $3.67 \pm 0.57$ sec prior to the reinforced response with a mean duration of $3.22 \pm 0.50 \mathrm{sec}$. The mean onset time for the second peak was $94 \pm 29 \mathrm{msec}$ following the response with a mean duration of $1.17 \pm 0.20 \mathrm{sec}$. The four individual cells showing $\mathrm{PR}+\mathrm{RF}$ firing patterns presented in Figure 5 illustrate differences in PR $+\mathrm{RF}$ cell firing patterns. Comparison of two $\mathrm{PR}+\mathrm{RF}$ cells recorded in different animals on the left of Figure 5 reveals an inverse relationship with respect to peak amplitude versus time epoch. The two neurons shown in the PEHs on the right portion of Figure 5 were recorded simultaneously in the same animal from different electrode locations within the NA. Differences with respect to peak amplitudes were therefore apparent within as well as across different animals; however, the same general dual peak firing pattern was always present.

\section{Relationships among different $N A$ cell types}

The neuronal firing patterns of $P R, R F_{E}$, and $R F_{I}$ neurons during water and cocaine reinforcement are presented in Figure 6 as composite PEHs summed over all cells of a specific type and normalized relative to each neuron's respective baseline firing rate. Distinct anticipatory increases in firing can be seen during both cocaine and water reinforcement sessions for PR cells, but 
Figure 7. Composite PEH similar to Figure 6 summed over all PR + RF cells ( $n=18$; in some cases firing prior to the first response of an FR4 or FR10 is shown). The composite PEH of normalized firing shows that the population of $\mathrm{PR}+\mathrm{RF}$ neurons exhibits a composite of the other three properties of NA cell types shown in Figure 6. Duration of drug infusion indicated by horizontal line below the PEH. Reinforced response is indicated by $R$ at dashed vertical line.

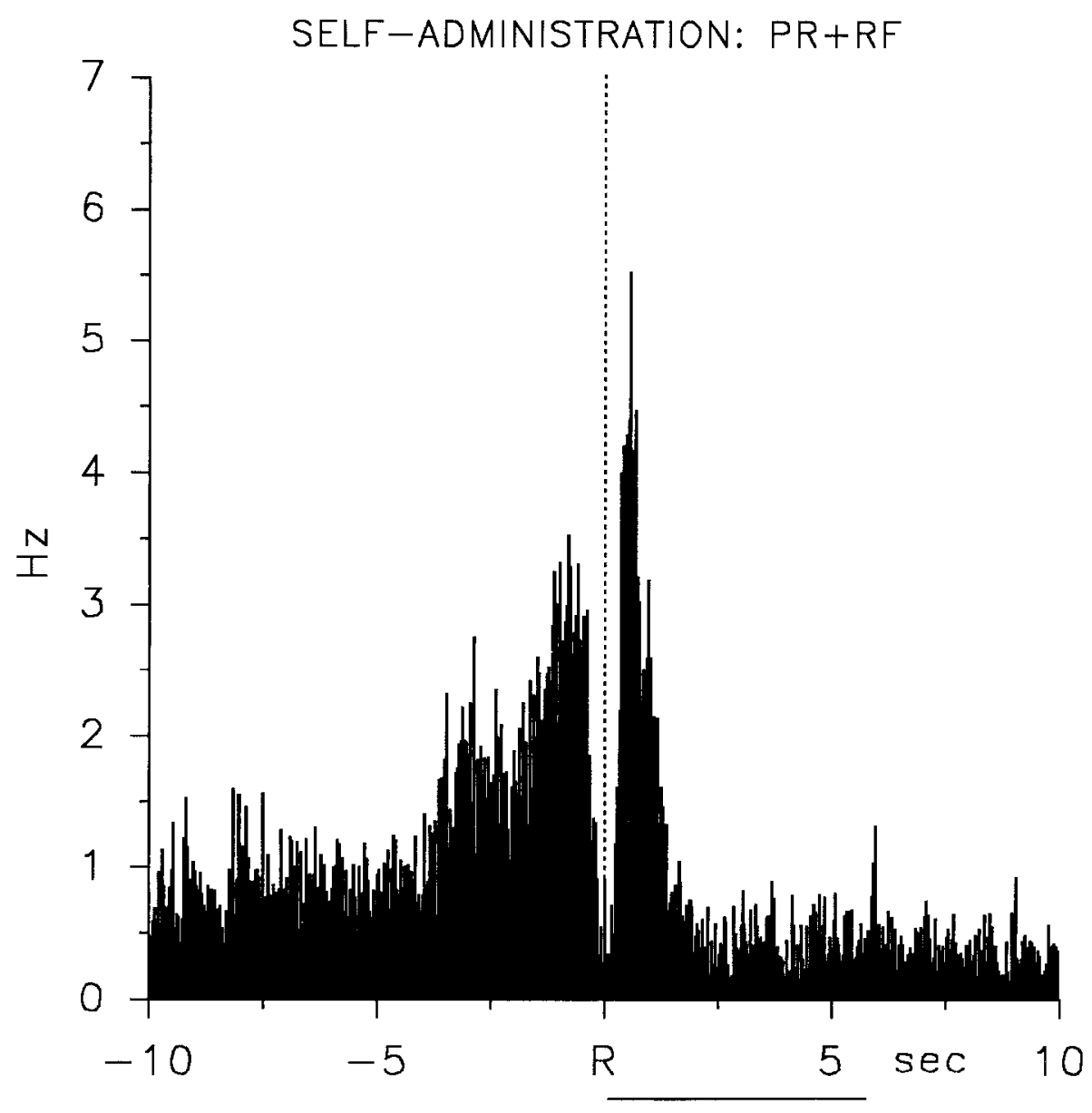

the increase was more dispersed and less defined for cocaine versus water. In addition, PR cells exhibited a sharper decline in firing rate at the response and a more rapid recovery of baseline firing after reinforcement delivery under water reinforcement conditions (Fig. 6).

The relative increase in firing rate of $R \Gamma_{E}$ cells during the reinforcement phase for water reinforcement sessions was nearly twice that for cocaine self-administration. In addition, $\mathrm{RF}_{\mathrm{E}}$ cells exhibited a more rapid return to baseline following the waterreinforced response. $\mathrm{RF}_{\mathrm{E}}$ cells exhibited less of an increase in firing rate following the cocaine-reinforced responses; however, in contrast to water $\mathrm{RF}_{\mathrm{E}}$ cells, firing rates remained elevated for at least $10 \mathrm{sec}$ following the response.

The composite summed PEHs for PR and $\mathrm{RF}_{\mathrm{E}}$ neuronal firing patterns (Fig. 6, top and middle) show that collectively, these two types of NA neurons exhibited marked increases in firing rate during and after the initiation and completion of the reinforced response. PR cells exhibited a ramp-like "anticipatory" increase in firing rate before the response that declined abruptly and severely at the time when $\mathbf{R F}_{\mathrm{E}}$ cells showed a marked increase in firing rate (Fig. 6, top and middle). The complementary nature of $P R$ and $R F_{E}$ cell firing was apparent in both water and cocaine reinforcement conditions, and suggests that these patterns represent two different populations of NA cells encoding different temporal aspects of the same behavioral event.

This complementary firing characteristic was also apparent in $\mathrm{RF}_{1}$ neurons (Fig. 6, bottom). In this case relatively high background firing rates were interrupted during the time at which
$P R$ and $R F_{E}$ cells were showing a large transition in firing. $R F_{I}$ normalized cell firing decreased significantly from baseline levels to near zero within $2.5 \mathrm{sec}$ during the time of peak firing in $\mathrm{RF}_{\mathrm{E}}$ cells. This pattern was present for $\mathrm{RF}_{\mathrm{I}}$ cells during both reinforcement conditions. Thus, it is clear from Figure 6 that at no time was there appreciable temporal overlap in the firing correlates of the three different NA cell types.

Elements of each of the above three cell types were also present in the composite PEHs of normalized firing for PR $+\mathrm{RF}$ cells $(n=18)$ shown in Figure 7 . Two distinct response (PR) and reinforcement $\left(R_{F}\right)$ firing peaks are present and sharply defined together with a distinct $\left(\mathrm{RF}_{\mathrm{I}}\right)$ interposed inhibitory period between the peaks at the time of the reinforced response. It is clear, therefore, that the composite PEH of PR $+\mathrm{RF}$ cells contains all the firing correlates present in the other three cell types and that these features also remain temporally segregated with respect to the phases of reinforced responding.

\section{Histology}

Detailed visual and computer assessment of $50 \mu \mathrm{m}$ sections from the brains of all 18 animals revealed that the microwire electrode arrays werc located primarily within the NA, and adjacent structures such as the ventral portion of the caudate-putamen (ventral striatum, VS), spanning a rostral-caudal distance of $1.50 \mathrm{~mm}$. Bilateral electrode placements ranged from +1.20 to $+2.70 \mathrm{~mm}$ anterior to bregma and from 0.40 to $2.4 \mathrm{~mm}$ lateral to the midline. Figure 8 shows electrode tip locations compiled across all subjects ( $n=18$ ) tested during both cocaine and water re- 


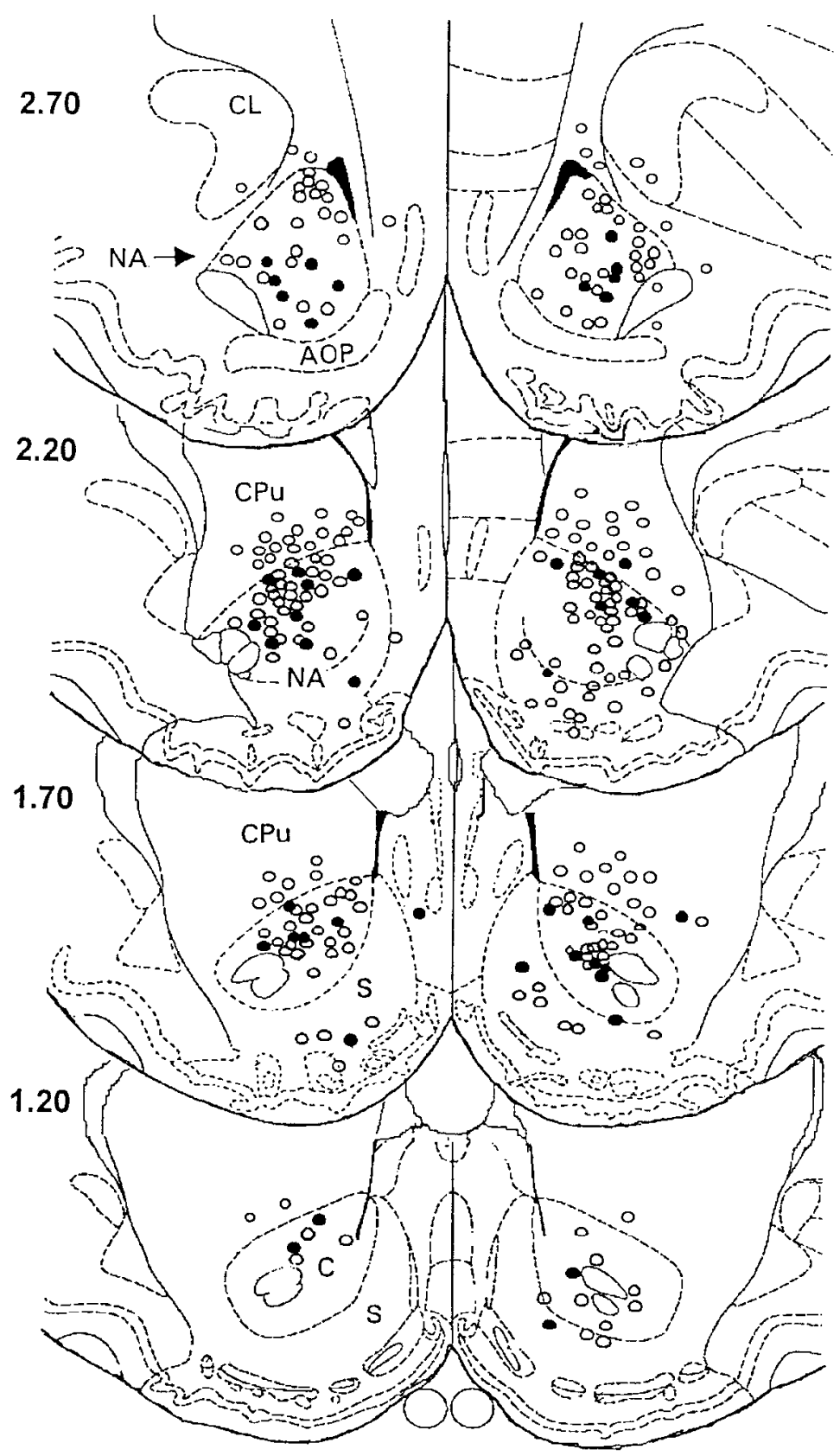

Figure 8. Coronal diagrams showing electrode tip and associated recording sites in or near the NA compiled across 18 animals. The range of placements was +1.20 to $+2.70 \mathrm{~mm}$ rostral to bregma. Darkened circles represent electrode locations that were marked by the presence of a bluc dot reaction product (Prussian blue) corresponding to the location of an electrode tip. Open circles represent unmarked electrode tip locations determined by examination of electrode tracks. Numbers to the left indicate AP coordinates in millimeters rostral to bregma. Diagrams were taken from the stereotaxic atlas of Paxinos and Watson (1986). NA, nucleus accumbens; $C L$, claustrum; $A O P$, anterior olfactory nucleus, posterior; $C P u$, caudate-putamen; $S$, nucleus accumbens, shell; $C$, nucieus accumbens, core.

inforcement sessions on coronal sections of the stereotaxic atlas of Paxinos and Watson (1986). The location of a blue dot reaction product, corresponding to the tip of an electrode (Green, 1958) from which an identified cell was recorded, is indicated by darkened circles in Figure 8. Flectrode tip locations that were not marked but estimated from the end of the electrode track in serial sections and are indicated by open circles in Figure 8.

A total of 293 electrode tracks (marked and unmarked) were identified within the NA and adjacent structures across 18 animals. Of the 293, 220 electrode tracks were determined to be within the NA, 173 unmarked and 47 marked. Of the 173 unmarked electrode locations within the NA, 44 were estimated to be within the rostral pole, 104 within the core, and 25 within the shell, as defined by Zahm and Brog (1992). Of the 47 marked placements within the NA, 11 were located within the rostral pole, 30 were estimated to be within the core, and six within the shell. Of the 47 marked locations, all four cell types were distributed throughout the rostral pole, core and shell subregions of the NA. Of the total 293 recovered electrode tips, 73 were clearly located outside the NA; 54 unmarked and two marked tips were located dorsally within the ventral striatum. The remaining 17 electrode tip locations were outside the NA and distributed within structures adjacent to the NA (Fig. 8).

\section{Discussion}

A major finding of the present study was that NA neurons exhibited similar types of firing patterns relative to the reinforced response during both cocaine self-administration and water reinforcement sessions. The three distinct firing patterns were observed in the same as well as across different animals despite pronounced behavioral and pharmacological differences between the two reinforcement conditions. The similarity in the 
temporal specificity of NA firing relative to the reinforced response in both conditions indicates that the phasically firing NA neurons are not dependent upon a particular behavioral response pattern or type of reinforcer, but instead appear to be more generally related to the act of approaching the lever and acquiring reward.

The majority of neurons exhibiting response-related activity during the initiation, execution, and completion of the reinforced response $\left(\mathrm{PR}, \mathrm{RF}_{\mathrm{E}}, \mathrm{RF}_{\mathrm{I}}, \mathrm{PR}+\mathrm{RF}\right)$ were recorded from electrodes located in the rostral pole, core, and shell of the NA. However, similar neuronal firing patterns were also recorded from a few sites adjacent to the NA, particularly within ventral striatum (VS). The finding that similar neuronal firing characteristics were observed in the NA and VS suggests that these cell types may exist within both structures, a finding consistent with reports of similarities in limbic structure projections to both regions (Groenewegen et al., 1987; Schultz et al., 1992). However, it is significant to note that phasically active neurons recorded in the NA and VS constituted at most only $25 \%$ of the total sample of neurons tested under both reinforcer conditions. Thus, the majority of neurons recorded both within and outside the NA exhibited no change in firing rate relative to the reinforced response. The specific firing correlates of the unaffected NA cells remain to be determined.

The finding that some NA neurons exhibit phasic activity relative to the reinforced response during cocaine self-administration supports the long-held contention that the NA, particularly the dopaminergic projection from the VTA to the NA, is involved in mediating the reinforcing properties of cocaine (Ettenberg et al., 1982; Wise, 1984; Koob et al., 1987; Koob and Bloom, 1988; Koob and Goeders, 1988; Wise and Rompre, 1989; Koob, 1992). For example, it has been reported that cocaine self-administration is attenuated in rats following selective dopaminergic lesions of the NA (Roberts et al., 1980; Pettit et al., 1984) or VTA (Roberts and Koob, 1982). In addition, pretreatment with dopamine antagonists increases cocaine self-administration in rats (deWit and Wise, 1977; Roberts and Vickers, 1984; Koob and Goeders, 1988; Britton et al., 1991; Corrigall and Coen, 1991; Hubner and Moreton, 1991; Maldonado et al., 1993). Likewise, microdialysis studies have shown a significant increase in NA dopamine, approximately $300 \%$ above baseline levels, during the early stages of the cocaine self-administration session in rats (Pettit and Justice, 1989, 1991). In this regard, it has been suggested that increased dopamine levels in the NA may be responsible for the spontaneous transition in NA firing patterns during the early trials of the self-administration session that correspond to the onset of stable interinfusion intervals (Carelli et al., 1993a,b). It is also possible, therefore, that the four types of neuronal firing patterns observed in the present study may be related to increased levels of dopamine within the NA during cocaine self-administration.

Several investigations have also implicated the mesoaccumbens dopamine system in mediation of the rewarding properties of "natural" reinforcers such as food and water. For example, in vivo microdialysis studies have shown increases in NA dopamine during food and water consumption in rats (Hernandez and Hoebel, 1988; Radhakishun et al., 1988; McCullough and Salamone, 1992; Young et al., 1992; McCullough et al., 1993). In addition, electrophysiological recordings in behaving animals showed that NA neurons exhibited phasic firing patterns during appetitively reinforced responding. In monkeys performing a delayed go-no go task, NA neurons increased firing rates, in- dependent of movement, prior to juice reinforcement delivery (Apicella et al., 1991; Schultz et al., 1992). Such neuronal firing patterns were attributed to "expectation" of the reinforcer since, for example, response-related firing patterns disappeared during trials in which the juice reinforcer was not presented, and was attenuated during trials in which the strength of the reinforcer was reduced by substitution of water for juice (Schultz et al., 1992). Likcwise, the present study showed increases in NA firing rate prior to response completion (PR and PR + RF cells; Table 1, Response) that appear to reflect "anticipation" or "expectancy" of the reinforcer. Such firing was dissociated from increased motor activity and unreinforced responding on higher ratio-type (FR4, FR10) reinforcement schedules (Carelli et al., 1993b).

Recently, Chang et al. (1994) reported similar phasic changes in firing of NA neurons during cocaine self-administration sessions. The anticipatory increases in firing reported by Chang and colleagues were similar in onset time and duration to those observed in the present study for PR cells, and for some $R_{E}$ cells. However, Chang and colleagues also reported that approximately $34 \%$ of NA neurons exhibited inhibitory responses after the cocaine-reinforced response, compared to $9 \%$ observed in the present study $\left(\mathrm{RF}_{\mathrm{I}}\right.$ cells). The basis for the differences in the number of neurons exhibiting postresponse inhibition could reflect differences in anatomical locations of recorded cells or differences in the behavioral protocols used in the two studies. Nevertheless, an important consistent finding in both studies was that the same "types" of NA neurons were observed.

The demonstration of response-related increases in the firing rates of NA neurons during cocaine self-administration contrasts with previous reports in anesthetized rats showing strong inhibitory actions of systemic or microiontophoretic application of cocaine on NA neurons (White et al., 1987; Henry et al., 1989; Qiao et al., 1990; White, 1990, 1993). From one perspective, however, the results of the present study are consistent with a suppressive action of cocaine on NA cell firing. Table 1 and Figures 2 and 3 show significant attenuation in the peak firing of PR- and $\mathrm{RF}_{\mathrm{E}}$-type cells during self-administration sessions as compared to water reinforcement. Since systemic levels of cocainc remain clevated throughout the session (Pettit and Justice, 1989, 1991), this may have "blunted" the excitatory responses of NA neurons. Nonetheless, the fact that excitatory responses were observed coincident with cocaine infusion $\left(R F_{E}\right.$, $\mathrm{PR}+\mathrm{PF}$ cells) suggests that NA neuronal reactivity in behaving animals cannot be extrapolated directly from pharmacological effects in anesthetized animals (Carelli et al., 1993b).

In the present study, the high degree of consistency with which the three types of cells were recorded in both reinforcement contexts supports an involvement of the NA in mediating the reinforcing properties of both psychomotor stimulants as well as "natural" appetitive reinforcers. Although it has not been definitively established, preliminary investigations in the monkey have shown that the same NA neuron can exhibit different firing patterns during cocaine- versus juice-reinforced responding (Aigner et al., 1993). This suggests that although similar firing patterns may be involved in mediating the rewarding properties of drugs and appetitive reinforcers, there may be a specificity within the functional circuitry of the NA that determines the precise conditions under which this occurs.

In this regard, the present study extends the characterization of a fourth type of neuronal firing pattern, the PR+RF cells observed as yet only during cocaine self-administration sessions 
(Carclli et al., 1993a,b). An important fcaturc of PR । RF cclls was that they exhibited all three features of response-related activity present in the other cell types $\left(P R, R F_{E}, R F_{I}\right)$. It is also quite possible that the emergence of the $P R+R F$ firing pattern resulted from behavioral differences between the two tasks (Fig. 1) and not from the direct action of the drug. Specifically, the longer INT in cocaine self-administration sessions reflected druginduced stereotypy that was not present during water sessions. The frequency with which this unique firing pattern was encountered suggests that cocaine produced (1) an activation of a completely different set of NA neurons that fire uniquely only with cocaine present or (2) a change in some PR or RF neurons to make them fire like PR $+\mathrm{RF}$ cells. The change could be induced by dopamine $\mathrm{D}_{1}$ and/or $\mathrm{D}_{2}$ receptor-mediated conductance changes on NA neurons (Uchimura and North, 1990; Surmeier et al., 1993). The finding that a fourth type of neuronal firing pattern was observed only during cocaine self-administration could provide the first electrophysiological evidence of a form of NA cell activity related specifically and uniquely to drug-reinforced behavior.

In summary, the fact that three different types of NA neurons are activated in a temporally specific and complementary manner in animals responding for water and cocaine reinforcement indicates a critical role of the NA in mediating the rewarding properties of "natural" reinforcers such as food and water, and in mediating the actions of drugs of abuse such as cocaine. However, several important issues remain to be determined regarding the nature and control of these firing patterns, including specificity of reinforcer type, conditioned versus unconditioned actions of drugs, the role of conditioned stimuli in these effects, and the pharmacological specificity in relation to underlying neurobiological processes. Resolution of the above issues will provide a more thorough understanding of the degree to which these differential firing patterns in NA neurons are responsible for "goal-seeking" behaviors.

\section{References}

Aigner TG, Bowman EM, Richmond BJ (1993) Neurons in rhesus monkey ventral striatum carry different signals regarding juice and cocaine reinforcentent. Suc Neurosci Abstr 19:1839.

Apicella P, Ljungberg T, Scarnati E, Schultz W (1991) Responses to reward in monkey dorsal and ventral striatum. Exp Brain Res 85: $491-500$.

Blackburn JR, Phillips AG, Jakubovic A, Fibiger HC (1986) Increased dopamine metabolism in the nucleus accumbens and striatum following consumption of a nutritive meal but not a palatable nonnutritive saccharin solution. Pharmacol Biochem Behav 25:10951100.

Britton DRP, Curzon RG, Mackenzie JW, Kebabian JEG, Williams X, Kerkman D (1991) Evidence for involvement of both D1 and D2 receptors in maintaining cocaine self-administration. Pharmacol Biochem Behav 39:911-915.

Carelli RM, King VC, DeadwylerSA (1993a) Firing patterns of nucleus accumbens neurons during cocaine self-administration and appetitive reinforcement in rats. Soc Neurosci Abstr 19:1857.

Carelli RM, King VC, Hampson RE, Deadwyler SA (1993b) Firing patterns of nucleus accumbens neurons during cocaine self-administration in rats. Brain Res 626:14-22.

Chang JY, Sawyer SF, Lee RS, Woodward DJ (1994) Electrophysiological and pharmacological evidence for the role of the nucleus accumbens in cocaine self-administration in freely moving rats. J Neurosci 14:1224-1244.

Corrigall WA, Coen KM (1991) Cocaine self-administration is increased by both D1 and D2 dopamine antagonists. Pharmacol Biochem Behav 39:799-802.

deWit H, Wise RA (1977) Blockade of cocaine reinforcement in rats with the dopamine receptor blocker pimozide but not with the nor- adrenergic blockers phentolamine or phenoxybenzamine. Can J Psychol/Rev Can Psychol 31:195-203.

Ettenberg A, Pettit HO, Bloom FE, Koob GF (1982) Heroin and cocaine intravenous self-administration in rats: mediation by separate neural systems. Psychopharmacology 78:204-209.

Gawin FH (1991) Cocaine addiction: psychology and neurophysiology. Science 251:1580-1585.

Gonzalez-Lima F, Helmstetter FJ, Agudo J (1993) Functional mapping of the rat brain during drinking behavior: a fluorodeoxyglucose study. Physiol Behav 54:605-612.

Green JD (1958) A simple microelectrode for recording from the central nervous system. Nature 182:962.

Groenewegen HJ, Vermeulen-Van Der Zee E, Te Kortschot A, Witter MP (1987) Organization of the projections from the subiculum to the ventral striatum in the rat. A study using anterograde transport of Phaseolus vulgaris leucoagglutinin. Neuroscience 23:103-220.

Heffner TG, Hartman JA, Seiden LS (1980) Feeding increases dopamine metabolism in the rat brain. Science 208:1168-1170.

Henry DJ, Greene MA, White FJ (1989) Electrophysiological effects of cocaine in the mesoaccumbens dopamine system: repeated administration. J Pharmacol Exp Ther 251:833-839.

Hernandez L, Hoebel BG (1988) Feeding and hypothalamic stimulation increase dopamine turnover in the accumbens. Physiol Behav 44:599-606.

Hubner CB, Moreton EJ (1991) Effects of selective D1 and D2 dopamine antagonists on cocaine self-administration in the rat. Psychopharmacology 105:151-156.

Koob GF (1992) Drugs of abuse: anatomy, pharmacology and function of reward pathways. Trends Pharmacol Sci 13:177-184.

Koob GF, Bloom FE (1988) Cellular and molecular mechanisms of drug dependence. Science 242:715-723.

Koob GF, Goeders NE (1988) Neuroanatomical substrates of drug self-administration. In: Neuropharmacological basis of reward (Liebman JM, Cooper SJ, eds), pp 214-263. New York: Oxford UP.

Koob GF, Vaccarino FJ, Amalric M, Swerdlow NR (1987) Neural substrates for cocaine and opiate reinforcement. In: Cocaine: clinical and biobehavioral aspects (Fischer $\mathrm{S}$, Raskin $\mathrm{A}$, Uhlenhuth $\mathrm{EH}$, eds), pp 80-108. New York: Oxford UP.

Maldonado R, Robledo P, Chover J, Caine SB, Koob GF (1993) D1 dopamine receptors in the nucleus accumbens modulate cocaine selfadministration in the rat. Pharmacol Biochem Behav 45:239-242.

McCullough LD, Salamone JD (1992) Involvement of nucleus accumbens dopamine in the motor activity induced by periodic food presentation: a microdialysis and behavioral study. Brain Res 592:29_ 36.

McCullough LD, Cousins MS, Salamone JD (1993) The role of nucleus accumbens dopamine in responding on a continuous reinforcement operant schedule: a neurochemical and behavioral study. Pharmacol Biochem Behave 46:581-586.

Paxinos G, Watson C (1986) The rat brain in stereotaxic coordinates, 2d ed. New York: Academic.

Peoples LL, West MO (1990) Effects of intravenous cocaine on single unit activity in the nucleus accumbens of freely-moving rats. Soc Neurosci Abstr 16:252.

Peoples LL, Wolske M, Dworkin SI, Smith JA, Deadwyler SA, West MO (1989) A method for recording single unit activity during i.v. self-administration of drugs in the freely moving rat. Soc Neurosci Abstr 15:1097.

Pettit HO, Justice JB Jr (1989) Dopamine in the nucleus accumbens during cocaine self-administration as studied by in vivo microdialysis. Pharmacol Biochem Behav 34:899-904.

Pettit HO, Justice JB Jr (1991) Effect of dose of cocaine self-administration behavior and dopamine levels in the nucleus accumbens. Brain Res 539:94-102.

Pettit HO, Ettcnberg A, Bloom FE, Koob GF (1984) Destruction of dopamine in the nucleus accumbens selectively attenuate cocaine but not heroin self-administration in rats. Psychopharmacology $84: 167-$ 173.

Qiao JT, Dougherty PM, Wiggins RC, Dafny N (1990) Effects of microiontophoretic application of cocaine, alone with receptor antagonists, upon the neurons of the medial prefrontal cortex, nucleus accumbens and caudate nucleus of rats. Neuropharmacology 4:379385 .

Radhakishun FS, van Ree JM, Westerink BHC (1988) Scheduled eating increases dopamine release in the nucleus accumbens of food- 
deprived rats as assessed with on-line brain dialysis. Neurosci Lett 85:351-356.

Roberts DCS, Koob GF (1982) Disruption of cocaine self-administration following 6-hydroxydopamine lesions of the ventral tegmental area in rats. Pharmacol Biochem Behav 17:901-904.

Roberts DCS, Vickers G (1984) Atypical neuroleptics increase selfadministration of cocaine: an evaluation of a behavioral screen for antipsychotic activity. Psychopharmacology 82:135-139.

Roberts DCS, Koob GF, Klonoff P, Fibiger HC (1980) Extinction and recovery of coctine self-administration following 6-hydroxydopamine lesions of the nucleus accumbens. Pharmacol Biochem Behav 12: 781-787.

Schultz W, Apicella P, Scarnati E, Ljungberg T (1992) Neuronal activity in monkey ventral striatum related to the expectation of reward. J Neurosci 12:4595-4610.

Surmeier JD, Reiner A, Levine MS, Ariano MA (1993) Are neostriatal dopamine receptors co-localized? Trends Neurosci 16:299-305.

Uchimura N, North RA (1990) Actions of cocaine on rat nucleus accumbens neurones in vitro. Br J Pharmacol 99:736-740.

White FJ (1990) Electrophysiological basis of the reinforcing effects of cocaine. Behav Pharmacol 1:303-315.

White FJ (1993) Electrophysiological effects of cocaine in the rat nucleus accumbens: microiontophoretic studies. J Pharmacol Exp Ther 266:1075-1084.
White FJ, Wachtel SR, Johansen PA, Einhorn LC (1987) Electrophysiological studies of the rat mesoaccumbens dopamine system: focus on dopamine receptor subtypes, interactions, and the effects of cocaine. In: Neurophysiology of dopaminergic systems-current status and clinical perspectives (Chiodo LA, Freeman AS, eds), pp $317-$ 365. New York: Lakeshore.

Wise RA (1984) Neural mechanisms of the reinforcing action of cocaine. NIDA Res Monogr 50:15-33.

Wise RA, Rompre PP (1989) Brain dopamine and reward. Annu Rev Psychol 40:191-225.

Woolverton WL, Johnson KM (1992) Neurobiology of cocaine abuse. Trends Pharmacol Sci 13:193-200.

Young AMJ, Joseph MH, Gray JA (1992) Increased dopamine release in vivo in nucleus accumbens and caudate nucleus of the rat during drinking: a microdialysis study. Neuroscience 48:871-876.

Zahm DS, Brog JS (1992) Commentary: on the significance of subterritories in the accumbens part of the rat ventral striatum. Neuroscience 50:751-767.

Zito KA, Vickers G, Roberts DCS (1985) Disruption of cocaine and heroin self-administration following kainic acid lesions of the nucleus accumbens. Pharmacol Biochem Behav 23:1029-1036. 